\title{
Direct Relationship of Fetal Carboxyhemoglobin with Hemolysis in Alloimmunized Pregnancies
}

\author{
J. A. WIDNESS, L. S. LOWE, D. K. STEVENSON, H. J. VREMAN, C. P. WEINER, M. HAYDE, \\ AND A. POLLAK
}

Departments of Pediatrics [J.A.W., L.S.L.] and Obstetrics and Gynecology /C.P.W.J. The University of Iowa, Iowa City, Iowa 52242-1083; Department of Pediatrics, Stanford University. Stanford, California 94305 [D.K.S., H.J.V.J; and Department of Neonatology, University Children's Hospital, 1090 Vienna, Austria [M.H., A.P.J

\begin{abstract}
Because carbon monoxide $(\mathrm{CO})$ is a byproduct of heme degradation and because placental diffusing capacity of $\mathrm{CO}$ is limited, we hypothesized that the concentration of $\mathrm{CO}$ transported in fetal blood as carboxyhemoglobin ( $\mathrm{HbCO}$ ) would correlate with the severity of fetal hemolytic disease. Fetal blood was obtained by cordocentesis and $\mathrm{HbCO}$ was measured by gas chromatography. The two primary study groups included control fetuses $(n$ $=26$ ) and fetuses of Coombs-positive mothers before in utero transfusion $(n=15)$. Compared with controls, fetuses with hemolytic disease had higher $\mathrm{HbCO}$ levels $(0.0111 \pm$ 0.0014 versus $0.0159 \pm 0.0072$ fraction of total $\mathrm{Hb}$, mean $\pm \mathrm{SD}, p<0.002$ ). In contrast, $\mathrm{HbCO}$ levels in simultaneously sampled maternal blood samples were not different in the control and alloimmune groups $[0.0110 \pm 0.0025(n$ $=20)$ versus $0.0115 \pm 0.0021(n=11)]$. There was a significant inverse correlation observed between fetal $\mathrm{HbCO}$ and $\mathrm{Hb}$ concentrations in the group with hemolytic disease $(r=-0.73, p<0.002)$ but not in controls. In fetuses with hemolytic disease, $\mathrm{HbCO}$ and bilirubin were highly correlated $(r=0.88, p<0.0001)$. Data from four anemic fetuses who were Coombs negative, three of whom had no evidence of hemolysis, indicated normal $\mathrm{HbCO}$ and normal plasma bilirubin levels. A fourth fetus with anemia had viral sepsis and elevated $\mathrm{HbCO}$ and plasma bilirubin levels. We conclude that elevated $\mathrm{HbCO}$ levels detected in fetuses of nonsmoking mothers with erythrocyte alloimmunization are likely the result of accelerated hemolysis. (Pediatr Res 35: 713-719, 1994)
\end{abstract}

Abbreviations

CO, carbon monoxide

$\mathrm{HbA}$, adult $\mathrm{Hb}$

HbCO, carboxyhemoglobin

$\mathrm{HbF}$, fetal $\mathrm{Hb}$

NRBC, nucleated red blood cell

After normal erythrocyte senescence or pathologic processes in which accelerated hemolysis occurs, $\mathrm{Hb}$ is degraded by the reticuloendothelial system to globin and heme $(1,2)$. Although breakdown of heme-containing proteins other than $\mathrm{Hb}$ contributes to endogenous $\mathrm{CO}$ and bilirubin production, these other proteins contribute only 15 to $25 \%$ of the total endogenous $\mathrm{CO}$ and bilirubin levels $(3,4)$. Degradation of heme by microsomal

Received June 25, 1993; accepted December 2, 1993.

Correspondence: John A. Widness, M.D.. Department of Pediatrics, The University of lowa, 200 Hawkins Drive W222-1 GH, lowa City, IA 52242-1083.

Supported by NIH USPHS Grants HL46925 (J.A.W.), HD14426 (D.K.S.), RR0008I (D.K.S.), HD24494 (C.P.W.), and HL4904I (C.P.W.) heme oxygenase results in cleavage of the porphyrin ring, yielding equimolar amounts of bilirubin, iron, and CO (5). Similar to oxygen, $\mathrm{CO}$ binds reversibly to $\mathrm{Hb}$ in circulating erythrocytes and in doing so forms $\mathrm{HbCO}$. Elimination of $\mathrm{CO}$ from the fetus via the placenta, or from postnatal individuals via the lungs, is slow because of CO's considerably greater affinity for $\mathrm{Hb}$ relative to oxygen and because of CO's limited gaseous exchange (6).

Fetuses of women affected by erythrocyte alloimmune disease are at risk for developing life-threatening anemia due to accelerated erythrocyte immune-mediated hemolysis (7). Elevated concentrations of $\mathrm{HbCO}$ have been reported at delivery in cord blood of human fetuses and in postnatal blood of newborn infants with immune hemolytic disease $(8-10)$. Thus far, studies have focused on term fetuses delivered after variable periods of labor. Because maternal $\mathrm{HbCO}$ levels are affected by anesthetics and alterations in maternal ventilation preceding delivery $(8,11$, 12), fetal HbCO levels at birth may be affected by these maternal perturbations. $\mathrm{HbCO}$ data in mid- to late-gestation human fetuses have not been reported.

The diagnostic and therapeutic use of cordocentesis has created the opportunity for studying the human fetus under undisturbed conditions from midgestation onward. In the present study, we hypothesized that, in the absence of maternal smoking, the rate of fetal hemolysis would be reflected by elevated $\mathrm{HbCO}$ levels, which in turn would be associated with the severity of fetal anemia and with other hematologic and biochemical indicators of hemolysis. To test this hypothesis, we studied anemic and nonanemic human fetuses undergoing clinically indicated cordocentesis. The two primary study groups consisted of control fetuses and fetuses of mothers with erythrocyte alloimmunization. Also examined were secondary study groups consisting of anemic Coombs-negative fetuses and fetuses of mothers who smoked tobacco.

\section{MATERIALS AND METHODS}

Appropriate institutional review for the use of human subjects in medical research was obtained at the University of Iowa and at the University of Vienna. Study subjects included consecutive fetuses undergoing clinically indicated cordocentesis who met study criteria. All mothers were in good health. HbCO levels were measured in all fetal and most maternal blood samples at the time of cordocentesis.

Primary Study Groups. Fetuses with immune hemolytic disease. Fifteen antigen-positive fetuses whose mothers had an indirect Coombs' titer $>8$ for erythrocyte antigens known to cause fetal hemolysis were studied. Eleven $(73 \%)$ underwent more than one diagnostic or therapeutic cordocentesis. Six (40\%) initially had, or later developed, anemia severe enough to necessitate one or more intravascular erythrocyte transfusions. Fetal transfusions were performed when the fetal hematocrit fell below 0.30 , a value $<2$ SD for fetuses at 20 wk gestation (13). Two 
fetuses had ultrasound evidence of hydrops at the time of their first cordocentesis; one died before fetal transfusion could be administered. There were no other fetal or neonatal deaths.

Control fetuses. Twenty-six control fetuses were derived from two subgroups: those who were normal $(n=8)$, and those who had morphologic evidence of one or more congenital abnormalities $(n=18)$. Assignment to the normal subgroup was done retrospectively once the potential fetal disorder necessitating cordocentesis was conclusively disproved. Indications for cordocentesis included suspicion of genetic abnormality $(n=2)$, maternal erythrocyte alloimmunization $(n=2)$, infectious exposure $(n=3)$, and maternal thyroid disease $(n=1)$. There were no fetal or neonatal deaths.

The remaining control subgroup consisted of 18 fetuses with identifiable congenital abnormalities. Because of the association of chromosomal abnormalities with fetal hematologic perturbations, fetuses with karyotypic anomalies were excluded. The predominant organ systems affected in these fetuses included the CNS $(n=7)$, the gastrointestinal tract $(n=6)$, the heart $(n=2)$, the kidney $(n=2)$, and the lung $(n=1)$. All had Hb concentrations and red blood cell counts that fell within the $95 \%$ confidence interval for normal fetuses of comparable gestational age (14). Although there were no fetal deaths, neonatal survival depended on the severity of the congenital lesion(s).

Secondary Comparison Groups. Fetuses with anemia due to nonimmune causes. During the period of study, four fetuses with Coombs-negative anemia were identified. None of the mothers smoked. Two were anemic donor twins in which a twin-to-twin transfusion had occurred. The third fetus had a large fetal-tomaternal hemorrhage. A fourth fetus had nonimmune hemolysis secondary to congenital viral infection. This fetus demonstrated a marked reticulocytosis, required three in utero transfusions, and died of multiple organ failure $5 \mathrm{~h}$ after birth.

Fetuses of smoking mothers. Because maternal smoking has a pronounced effect on maternal and fetal HbCO levels (11), 13 fetuses whose mothers gave a history of smoking one or more cigarettes per day were studied as a reference group. None had alloimmune disease. Three of these fetuses fulfilled the same criteria as the normal control subgroup; 10 others were affected by morphologic abnormalities similar to the subgroup with congenital anomalies. Although there were no fetal deaths, neonatal survival depended on the severity of the congenital lesion(s).

Cordocentesis Procedure. Fetal blood was obtained under ultrasound guidance, using a 22- or 25-gauge spinal needle of the appropriate length (15). Venous samples were preferred to arterial samples for reasons of safety. This was possible in all but a few patients. Contamination of fetal blood with maternal blood was excluded by determination of hematologic parameters, i.e. Kleihauer-Betke testing and hematologic indexes by automated cell counter (16).

Laboratory Determinations. Blood testing other than for $\mathrm{HbCO}$ on cordocentesis samples was performed in the hospitals' clinical laboratories. Erythrocyte and leukocyte counts were determined using an automated blood counter (Technicon-H-1 Autoanalyzer, Miles, Inc., Tarrytown, NY). The reticulocyte count was performed manually by scoring 1000 erythrocytes stained with brilliant cresyl blue and viewed on a Miller disk. The NRBC count was calculated from the total leukocyte count and the number of NRBC per 100 leukocytes. Plasma total and direct bilirubin levels were measured spectrophotometrically using a commercial assay (Boehringer-Mannheim, Indianapolis, IN) on an autoanalyzer (Hitachi model 737, Boehringer-Mannheim).

$\mathrm{HbCO}$ concentrations in blood samples (120-140 $\mu \mathrm{L})$ were determined at Stanford University with a sensitive gas chromatographic method within 1 mo of storage at $4^{\circ} \mathrm{C}(17,18)$. Briefly, $2 \mu \mathrm{L}$ of blood were injected in triplicate into $2-\mathrm{mL}$ septumsealed, CO-free vials with $20 \mu \mathrm{L}$ of $10 \%$ (wt/vol) $\mathrm{K}_{3} \mathrm{Fe}(\mathrm{CN})_{6}$ in $0.1 \mathrm{M}$ potassium phosphate buffer, pH 6.0 , containing $1 \%$ (wt/ vol) saponin. The vials were incubated at $0^{\circ} \mathrm{C}$ for at least $30 \mathrm{~min}$ but not longer than $1 \mathrm{~h}$. The $\mathrm{CO}$ liberated into the vial headspace was then injected into the gas chromatograph with a reduction gas detector (model RGA2; Trace Analytical, Inc., Menlo Park, $\mathrm{CA})$. The $\mathrm{CO}$ was separated from other compounds on a $68 \times$ $0.53 \mathrm{~cm}$ (inner diameter) molecular sieve column at $125^{\circ} \mathrm{C}$ with a carrier gas flow rate of $50 \mathrm{~mL}$ of $\mathrm{CO}$-free air per minute. The analyzer was standardized before and after each run with volumes of standard gas containing $25.0 \mu \mathrm{L} \mathrm{CO} / \mathrm{L}$ of $\mathrm{N}_{2}$ (Airco Air and Specialty Gases, Santa Clara, CA). The within-day and betweenday coefficients of variation for reference blood samples using this method are $3 \%$ and $8 \%$, respectively. The minimum detectable concentration is $0.00005 \mathrm{HbCO}$. $\mathrm{HbCO}$ concentrations are expressed as a fraction of the total $\mathrm{Hb}$ saturation.

$\mathrm{HbCO}$ levels were not corrected for $\mathrm{CO}$ present in inhaled air (19). Information regarding exposure of pregnant subjects to passive cigarette smoking or exogenous $\mathrm{CO}$ within the home environment or just before their clinic visit was not obtained. However, data on environmental levels of $\mathrm{CO}$ in the proximity of the two study hospitals were obtained. Neither hospital permitted smoking within its patient care areas.

Concentrations of $\mathrm{Hb}$ used in the $\mathrm{HbCO}$ determinations were measured with a manual cyanmethemoglobin method (kit no. 525 , Sigma Chemical Co., St. Louis, MO) (20). Four $\mu$ L of blood, pipetted with a Hamilton gastight syringe in a Hamilton repeating dispenser (Hamilton Co., Reno, NV), were allowed to react with $2.0 \mathrm{~mL}$ of Drabkin's reagent for a minimum of $2 \mathrm{~h}$ at room temperature. The absorbency of the resultant cyanmethemoglobin was determined at $540 \mathrm{~nm}$ with a spectrophotometer (model UV-160, Shimadzu Scientific Instruments Inc., Columbia, MD). The within-day and between-day coefficients of variation for reference blood samples using this method are $2.2 \%$ and $3.0 \%$, respectively.

Data Analysis and Statistical Methods. Although the majority of the fetuses with hemolytic disease, and a few of the controls, had multiple cordocenteses performed, the individual fetus' blood samples used in the group analyses were the pretransfusion samples having the lowest $\mathrm{Hb}$ concentrations. This provided the greatest spectrum of anemia without erroneously inflating the number of degrees of freedom. For fetuses with hemolytic disease who received tranfusions, this sample corresponded to the one taken immediately before the first in utero transfusion.

Statistical analyses were performed using a microcomputer software program (StatView 4.0, Abacus Concepts, Inc., Berkeley, CA). Results are presented as the mean \pm SD. Betweengroup comparisons for two groups were done using unpaired $t$ tests or the Mann-Whitney $U$ test for normally or nonnormally distributed data, respectively. For comparison of more than two groups, a one-factor analysis of variance was used. Analysis of variance comparisons in which the $F$ values were significant were subjected to post hoc examination using Dunnett's two-tailed procedure. Simple and multiple linear regressions were used to examine possible associations of study variables within individual groups of fetuses. The alpha level of significance selected was $p$ $<0.05$.

\section{RESULTS}

Atmospheric measurements of $\mathrm{CO}$ taken in the room in which the fetal cordocenteses were done at the University of Iowa Hospitals and Clinics averaged $0.76 \pm 0.30 \mathrm{ppm}$. CO levels taken in Vienna near the University Hospital averaged $0.77 \pm 0.19$ ppm. For previous studies, we reported sample $\mathrm{HbCO}$ stability for at least 2 mo $(17,18)$. During the present study, we routinely analyzed reference samples stored at $4^{\circ} \mathrm{C}$ for up to $365 \mathrm{~d}$. Regression analysis of the $\mathrm{HbCO}$ content of these samples versus sample age yielded the following relationship: $\mathrm{HbCO}=0.00015 \mathrm{~d}+$ $0.07, r^{2}=0.038, p=$ NS.

Subgroup comparisons. Blood $\mathrm{HbCO}$ levels in the two subgroups of control fetuses were statistically indistinguishable: $0.0107 \pm 0.0012$ for the normal controls, and $0.0113 \pm 0.0015$ 
for those controls having congenital anomalies (Fig. 1). There was a slight but nonsignificant difference in their gestational ages ( $24.8 \pm 6.4$ versus $30.1 \pm 6.2 \mathrm{wk}$, respectively). When adjusted for gestational age, there were no differences between these two control subgroups for plasma total bilirubin, $\mathrm{Hb}$ concentration, erythrocyte count, reticulocyte count, NRBC count, or leukocyte count.

Between-group comparisons. Data from the combined control group were compared with those of the immune hemolytic disease group (Table 1). Gestational ages of these two primary study groups were not statistically different $(28.5 \pm 6.6$ versus $28.7 \pm 5.4 \mathrm{wk})$. As anticipated, blood $\mathrm{Hb}$ concentration was significantly lower in the group with immune hemolytic disease. Significantly higher mean values were observed for $\mathrm{HbCO}$ (Fig. 1) and total plasma bilirubin in this group. Direct bilirubin levels were not elevated in any of the fetuses with immune hemolytic disease $(3.93 \pm 2.22 \mu \mathrm{mol} / \mathrm{L}$, range $1.7-8.6 \mu \mathrm{mol} / \mathrm{L})$. No between-group differences were observed for either reticulocyte (absolute or fraction) or NRBC counts. There were no differences between the maternal $\mathrm{HbCO}$ levels for the control group compared with the group with alloimmune disease $[0.0110 \pm 0.0025$ $(n=20)$ versus $0.0115 \pm 0.0021(n=11)$, respectively].

All three of the Coombs-negative anemic fetuses who had maternal and fetal laboratory data consistent with a nonhemolytic process had $\mathrm{HbCO}$ and plasma bilirubin levels within the normal range $(0.0126,0.0134$, and $0.0094 \mu \mathrm{mol} / \mathrm{L}$ and 22.2 , 17.1 , and $30.8 \mu \mathrm{mol} / \mathrm{L}$, respectively). The fourth Coombs-negative fetus had a congenital viral infection, was thrombocytopenic, and had elevated $\mathrm{HbCO}$ and bilirubin levels equivalent to those observed in subjects with immune hemolytic anemia $(0.0237$ and $124.8 \mu \mathrm{mol} / \mathrm{L}$, respectively).

HbCO levels in fetuses of smoking mothers were markedly elevated $(0.0567 \pm 0.0320, n=13)$ compared with those in the two primary groups in which the mothers did not smoke $(p<$ 0.01 ). Mean maternal $\mathrm{HbCO}$ level in the group of mothers who smoked was $0.0392 \pm 0.0186(n=10)$, a value that was signifi-

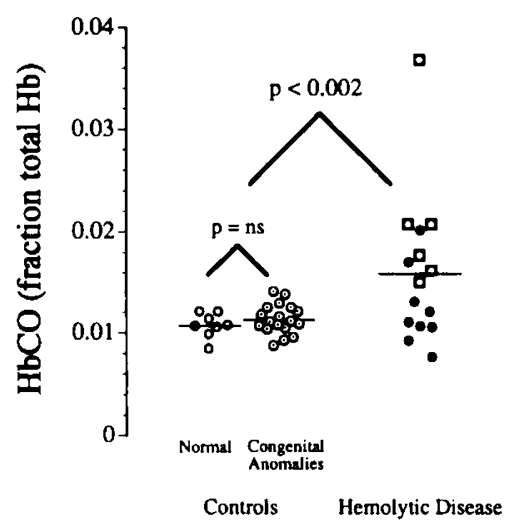

Fig. 1. Comparison of blood HbCO levels in the two fetal study groups: $l$ ) control fetuses including two subgroups-those retrospectively identified as normal $(O, n=8)$ and those with congenital anomalies but with normal hematologic indices $(\odot, n=18)$; and 2) fetuses with hemolytic disease due to fetal alloimmune disease $(n=15)$ including those who underwent transfusion (D) and those who were not $(\boldsymbol{\theta})$. The horizontal lines indicate the mean value for the study groups. cantly higher than the maternal values of the two primary study groups $(p<0.01)$.

Relationship of fetal $\mathrm{HbCO}$ with laboratory measurements: group data. There was no significant association of $\mathrm{HbCO}$ with gestational age for either the control or immune hemolytic disease group (Fig. 2). Similarly, in the control group, $\mathrm{HbCO}$ was not associated with any of the laboratory parameters including $\mathrm{Hb}$, bilirubin, reticulocyte count, and NRBC count.

In fetuses with immune hemolytic disease, significant associations were observed for $\mathrm{HbCO}$ with $\mathrm{Hb}(r=-0.73, p=0.002$; Fig. $3 A)$ and for $\mathrm{HbCO}$ with total plasma bilirubin $(r=0.88, p$ $<0.0001$; Fig. $3 B$ ). HbCO was not associated with the fraction of reticulocytes (in relation to total red blood cell count) or with the absolute reticulocyte count $(r=0.49, p=0.06$, and $r=$ $-0.31, p=0.25$, respectively). Total bilirubin was inversely associated with $\mathrm{Hb}$ level $(r=-0.66, p<0.01$; Fig. $3 C)$. Qualitatively similar statistical results were obtained when the differences between the fetal and maternal $\mathrm{HbCO}$ values were substituted for fetal $\mathrm{HbCO}$ levels. Because not all maternal samples were available, the number of paired data available for these analyses was smaller.

Although for the control group there was no association of $\mathrm{HbCO}$ with gestational age, significant gestational age associations were observed for $\mathrm{Hb}(r=0.59, p<0.002)$, plasma total bilirubin $(r=0.50, p<0.03)$, reticulocyte fraction $(r=-0.69$, $p<0.001)$, and absolute reticulocyte count $(r=-0.81, p<$ 0.001 ). To determine which of these laboratory variables were primarily associated with $\mathrm{HbCO}$ in the group with hemolytic disease, four separate multiple regression analyses were examined in which gestational age was entered as an independent variable along with $\mathrm{Hb}$, plasma total bilirubin, reticulocyte fraction, or absolute reticulocyte count. The $\beta$ coefficients were statistically significant for $\mathrm{Hb}(p<0.001)$ and plasma total bilirubin $(p<$ 0.0001 ) but not for gestational age. Although the $\beta$ coefficients for reticulocyte fraction and gestational age were both significantly associated with $\mathrm{HbCO}$ when entered together $(p<0.01$ and $p<0.05$, respectively), neither was significant for the combination of absolute reticulocyte count and gestational age.

When gestational age, $\mathrm{Hb}$, plasma total bilirubin, and reticulocyte fraction were entered together into a single multiple regression with $\mathrm{HbCO}$ as the dependent variable, only total plasma bilirubin's $\beta$ coefficient was found to be significantly associated $(p<0.02)$.

Relationships of $\mathrm{HbCO}, \mathrm{Hb}$, and bilirubin in individual fetuses with alloimmune disease. Data for five individual fetuses with immune hemolytic disease who underwent several cordocenteses before undergoing transfusion were available for examination of the relationship of $\mathrm{HbCO}$ with other laboratory variables. The findings were consistent with the results of the group correlations: 1) the slope of the linear regression plot for $\mathrm{HbCO}$ versus bilirubin for each of the five demonstrated a positive slope (Fig. $4 A$ ); and 2) each fetus demonstrated inverse associations of $\mathrm{HbCO}$ and total bilirubin with $\mathrm{Hb}$ (Fig. $4 B$ and $C$ ).

The two severely anemic Coombs-positive fetuses with hydrops at the time of the first visit could not be analyzed in the above manner because each had only a single value. Both had $\mathrm{HbCO}$ levels that were unexpectedly low relative to their $\mathrm{Hb}$ level (Fig. $3 A$ ). The total bilirubin level was available for only one of the two. In this fetus, the bilirubin value was low for the fetus's $\mathrm{Hb}$ level (Fig. $3 C$ ) but commensurate with its $\mathrm{HbCO}$ level (Fig. $3 B$ ).

Table 1. Comparison of pretransfusion fetal laboratory data in primary study groups (mean $\pm S D$ )*

\begin{tabular}{lccccccc}
\hline \multicolumn{1}{c}{ Group } & $n$ & $\begin{array}{c}\mathrm{Hb} \\
(\mathrm{mmol} / \mathrm{L})\end{array}$ & $\begin{array}{c}\mathrm{HbCO} \\
(\text { fraction of total } \mathrm{Hb})\end{array}$ & $\begin{array}{c}\text { Bilirubin } \\
(\mu \mathrm{mol} / \mathrm{L})\end{array}$ & $\begin{array}{c}\text { Reticulocytes } \\
\left(\times 10^{8} / \mathrm{L}\right)\end{array}$ & $\begin{array}{c}\text { Reticulocytes } \\
(\text { fraction of RBC) }\end{array}$ & $\begin{array}{c}\text { NRBC } \\
\left(\times 10^{8} / \mathrm{L}\right)\end{array}$ \\
\hline $\begin{array}{l}\text { Controls } \\
\begin{array}{l}\text { Immune hemolytic dis- } \\
\text { ease }\end{array}\end{array}$ & 26 & $7.8 \pm 1.1$ & $0.0111 \pm 0.0014$ & $27.4 \pm 6.7$ & $2.41 \pm 0.95$ & $0.088 \pm 0.046$ & $3.96 \pm 2.79$ \\
$\begin{array}{l}p \text { value } \\
\text { value }\end{array}$ & $5.8 \pm 2.3$ & $0.0159 \pm 0.0072$ & $58.1 \pm 34.9$ & $2.05 \pm 1.24$ & $0.102 \pm 0.054$ & $4.06 \pm 2.99$ \\
& & $<0.001$ & $<0.01$ & $<0.001$ & NS & NS & NS \\
\hline
\end{tabular}

* RBC, red blood cells. 


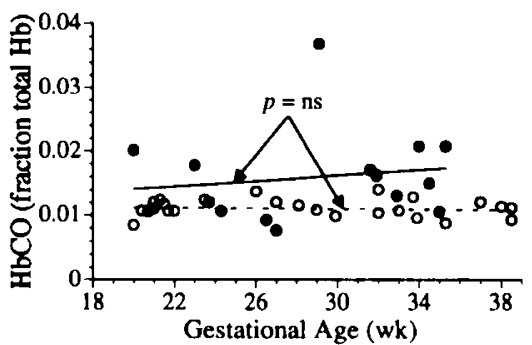

Fig. 2. Gestational age $v s \mathrm{HbCO}$ in control fetuses $(\mathrm{O}, n=26)$ and in fetuses with immune hemolytic disease $(0, n=15)$. The dashed line represents the regression analysis of the control fetuses and the solid line represents the regression analysis of the affected fetuses.

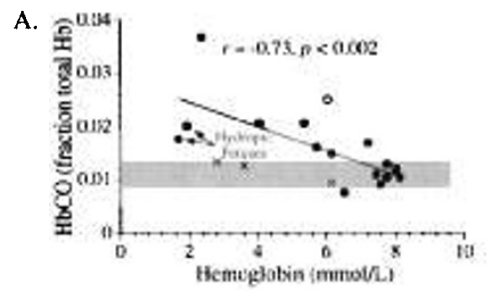

B.
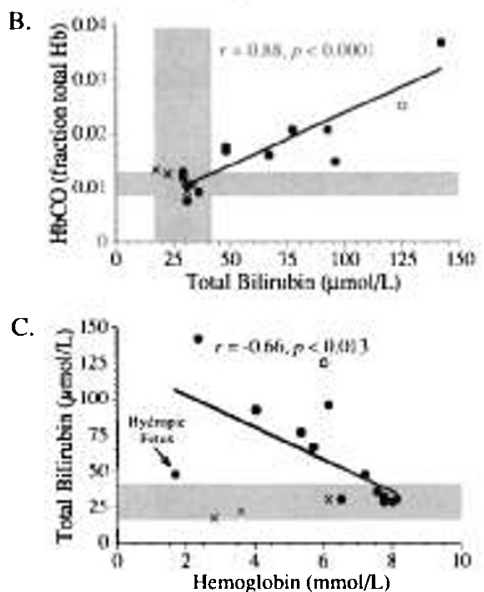

Fig. 3. Correlation of laboratory parameters in fetuses with immune hemolytic disease $(\theta)$. Fetuses that were anemic due to nonimmune causes are also shown but are not included in the regression analysis $(x$ $=$ fetal hemorrhage and $\mathrm{O}=$ fetal viral infection): $A$ ) $\mathrm{HbCO} v s \mathrm{Hb}$ concentration $(n=15) ; B) \mathrm{HbCO} v s$ total plasma bilirubin concentration $(n=13)$; and $C$ ) plasma bilirubin concentration vs $\mathrm{Hb}$ concentration ( $n$ $=13$ ). The shaded areas indicate the \pm 2 SD range for the control fetuses for the variables shown. The variable to which the shading applies is that of the axis from which it extends.

Four fetuses had multiple cordocenteses but had hematocrit values above 0.30 and thus did not undergo transfusion. In all four, $\mathrm{HbCO}$ and total bilirubin levels were within, or just above, \pm 2 SD value for the control group (data not shown).

Posttransfusion $\mathrm{HbCO}$ perturbations in individual fetuses with alloimmune disease. In three of the six fetuses with hemolvtic anemia who underwent transfusion, laboratory data were obtained at the time of subsequent cordocenteses for periods of 2 , 4 , and 10 wk. In each case, elevated levels of fetal $\mathrm{HbCO}$ and plasma bilirubin normalized as fetal erythrocytes were progressively replaced with donor cells. These events are best illustrated by examination of the fetus who had the highest pretransfusion $\mathrm{HbCO}$ and plasma total bilirubin levels and who was underwent transfusion three times (Fig. 5). When first studied at $26.5 \mathrm{wk}$, this fetus had hematocrit, HbCO, and plasma total bilirubin levels that were within the normal range. Two weeks later, at the time of the second cordocentesis, hematocrit had fallen to 0.33 and $\mathrm{HbCO}$ and plasma total bilirubin levels had abruptly risen

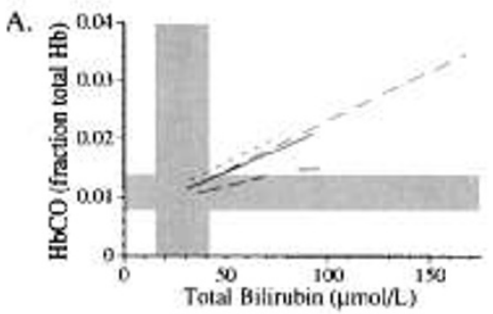

B.
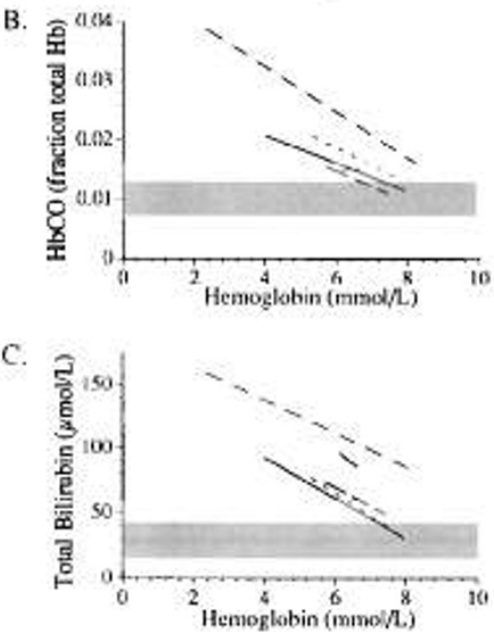

Fig. 4. Preerythrocyte transfusion linear regression relationships for the five individual fetuses who had hemolytic disease severe enough to require an intrauterine transfusion and who had at least two cordocenteses before their first transfusion: $A$ ) $\mathrm{HbCO} v s$ total bilirubin; $B$ ) $\mathrm{HbCO} v s \mathrm{Hb}$; and $C$ ) plasma total bilirubin $v s \mathrm{Hb}$. The dimensions of each regression line define the range of values observed for the individual fetuses. The shaded areas indicate the normal ranges for the values as explained in the legend to Figure 3.

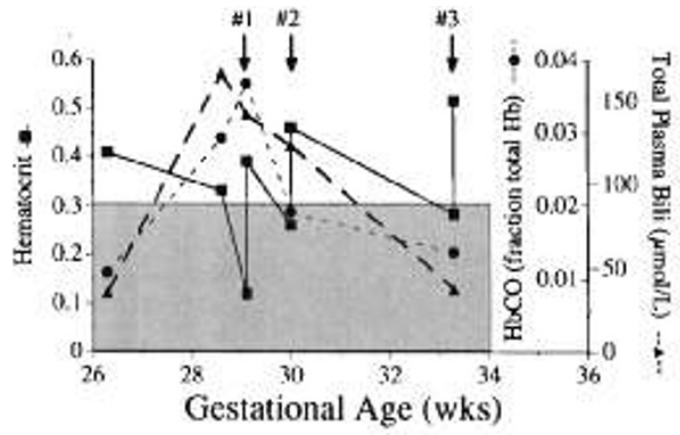

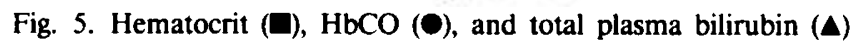
data over time in an individual fetus with Coombs-positive hemolytic disease who underwent repeated cordocenteses and received three in utero blood transfusions (numbered arrows) for the treatment of anemia. Transfusions were administered whenever fetal hematocrit fell to below 0.30 (shaded area). HbCO and total bilirubin both increased as fetal hematocrit fell. The former two subsequently declined as hematocrit rose after each of the three transfusions.

to 0.0292 and $167.6 \mu \mathrm{mol} / \mathrm{L}$, respectively. The following week, this fetus' hematocrit level fell precipitously to 0.12 , whereas $\mathrm{HbCO}$ and plasma total bilirubin levels remained near their zenith $(0.0368$ and $141.9 \mu \mathrm{mol} / \mathrm{L}$, respectively). One week after the first erythrocyte transfusion, there was a decline in both $\mathrm{HbCO}$ and bilirubin concentrations. By the third transfusion, the fetus' HbF levels had fallen to zero (data not shown), and $\mathrm{HbCO}$ and bilirubin levels had both normalized.

\section{DISCUSSION}

The severity of fetal anemia secondary to maternal alloimmunization and the rapidity of the hemolytic process are pres- 
ently unpredictable. When fetal anemia due to alloimmunization becomes profound, life-threatening fetal cardiac and hepatic failure result in fetal hydrops. Recently, cordocentesis has been used with increasing success to diagnose and treat fetal anemia secondary to maternal alloimmune disease (15). The observation that increased bilirubin levels in fetuses and neonates with $\mathrm{Rh}$ and $\mathrm{ABO}$ disease are the direct result of hemolysis forms the basis for measuring bilirubin concentrations in amniotic fluid to monitor the severity of fetal anemia in affected pregnancies (7). More recently, plasma bilirubin levels measured at cordocentesis have been shown to be associated with the severity of fetal hemolytic anemia (21). Similar studies of CO, another metabolic breakdown product of $\mathrm{Hb}$, have not previously been reported in undisturbed human fetuses with hemolytic disease.

Relationship of $\mathrm{HbCO}$ levels to fetal hemolysis. Under normal physiologic conditions and in the absence of excessive exogenous sources of $\mathrm{CO}, e . g$. air pollution and cigarette smoke, $75-85 \%$ of the $\mathrm{CO}$ measured as $\mathrm{HbCO}$ in blood is endogenously derived from erythrocyte breakdown $(3,4)$. Elevated $\mathrm{HbCO}$ levels have been associated with a variety of pathologic hemolytic conditions, among them hemolytic disease of the newborn (22-24). In the absence of exogenous $\mathrm{CO}$ sources, $\mathrm{HbCO}$ blood levels in nonpregnant individuals reflect the combined dynamic effects of $\mathrm{CO}$ production and elimination and of $\mathrm{HbA}$ 's affinity for $\mathrm{CO}$. Although under normal steady state conditions measurements of $\mathrm{CO}$ excretion in expired breath provide accurate indicators of hemolysis, measurements of static concentrations of $\mathrm{HbCO}$ provide good relative indirect assessments of this parameter (19).

The interpretation of steady state HbCO levels in the fetus and pregnant mother are complicated further by additional factors that include endogenous fetal $\mathrm{CO}$ production, different affinities of $\mathrm{HbF}$ and $\mathrm{HbA}$ for $\mathrm{CO}$ and oxygen, and gaseous exchange of $\mathrm{CO}$ across the placenta (11). Although direct measurement of the individual fetal and maternal $\mathrm{CO}$ contributions in expired maternal breath has not been possible, it is likely that per kilogram production rates are higher in both fetuses and pregnant women (6). Unlike oxygen affinity, which is increased with $\mathrm{HbF}$ relative to $\mathrm{HbA}$, affinity of $\mathrm{HbF}$ for $\mathrm{CO}$ in the human is only slightly lower (25). On the basis of studies in nonanemic fetal sheep in which exogenous $\mathrm{CO}$ was administered to ewes, the placenta has been shown to significantly retard gaseous exchange of $\mathrm{CO}$ (11). Half-life elimination rates of $\mathrm{CO}$ in mothers and fetuses in these experiments were reported as 2 and $7 \mathrm{~h}$, respectively. Along with changes in maternal ventilation during pregnancy, each of these factors affects the absolute and relative concentrations of $\mathrm{HbCO}$ in fetal and maternal blood.

Despite this multiplicity of factors affecting fetal and maternal $\mathrm{HbCO}$ levels, under steady state conditions, gradual increases in $\mathrm{HbCO}$ levels over a matter of days to weeks likely reflect increases in $\mathrm{CO}$ production. Because the mothers in the present study were all normal, changes observed in fetal $\mathrm{HbCO}$ concentrations would most likely reflect changes in the rate of fetal hemolysis.

Steady state $\mathrm{HbCO}$ conditions were likely present in our control and hemolytic disease groups but probably not in our group in which the mothers smoked (11). Fetuses in the latter group were most likely repeatedly exposed to abruptly increased concentrations of maternal $\mathrm{HbCO}$ as a result of exogenous $\mathrm{CO}$ in cigarette smoke. The magnitude and rapidity of these changes, i.e. minutes to hours, in blood of fetuses whose mothers smoked would render their $\mathrm{HbCO}$ levels meaningless as estimates of fetal hemolysis.

Previous investigations have demonstrated that $\mathrm{HbCO}$ levels in umbilical cord blood at delivery are increased in fetuses with $\mathrm{Rh}$ or $\mathrm{ABO}$ hemolytic disease $(8,10)$. Similarly, neonates with immune hemolytic disease also demonstrated elevated $\mathrm{HbCO}$ levels during the first week of life $(8,9,26)$. However, ours is the first study to report $\mathrm{HbCO}$ data in undisturbed mid- to lategestation anemic and nonanemic human fetuses. The significantly increased $\mathrm{HbCO}$ levels we observed in fetuses with immune hemolytic disease are of the same magnitude as those reported in previous fetal and neonatal studies. Because maternal levels of $\mathrm{HbCO}$ in the control and alloimmune groups were not different from one another or from their fetal counterparts, it is unlikely that passive exposure to cigarette smoke or to other unidentified environmental sources of $\mathrm{CO}$ would have confounded our results.

In addition to $\mathrm{HbCO}$ levels being elevated in fetuses affected by maternal alloimmunization, a dose effect of anemia on $\mathrm{HbCO}$ was observed, i.e. fetal $\mathrm{HbCO}$ levels were directly correlated with the severity of fetal anemia. In a study of 26 neonates with immune hemolytic disease, Fällström and Bjure (8) also observed an inverse correlation of $\mathrm{HbCO}$ and $\mathrm{Hb}$ levels during the first 12 $\mathrm{h}$ of life. In two other studies, increased CO excretion in expired breath of infants with immune hemolytic disease was demonstrated $(9,26)$. These data suggest that hemolysis due to maternal alloimmunization causes increased fetal and neonatal $\mathrm{CO}$ production.

Additional support for hemolysis secondary to maternal alloimmunization causing increased fetal and neonatal $\mathrm{CO}$ production is the significant direct association observed between $\mathrm{HbCO}$ and plasma bilirubin. Because $\mathrm{CO}$ and bilirubin are produced in equimolar amounts during heme degradation, one would anticipate that $\mathrm{HbCO}$ and bilirubin would be associated with one another. Consistent with this was our finding that the two most highly associated variables were $\mathrm{HbCO}$ and plasma bilirubin. This observation was supported by the results of our multiple regression analyses and by the work of previous investigators $(8,10)$.

Although $\mathrm{CO}$ excretion in maternal breath was not measured in the present study, it might be of interest to determine whether this information would provide a noninvasive means for indirectly assessing the severity of fetal hemolysis. Because of the mother's vastly larger $\mathrm{Hb}$ mass, the increase in fetal $\mathrm{CO}$ production resulting from pathologic hemolysis might be diluted to the extent that measurable differences are not demonstrable. Our observation that nonsmoking mothers of fetuses with hemolytic disease tended to have slightly higher $\mathrm{HbCO}$ levels than control mothers suggests that this possibility might be worth pursuing.

Laboratory data of individual fetuses in the present study were uniformly consistent with the group associations noted above. Of the nine fetuses with alloimmune disease who were never sufficiently anemic to receive transfusions, seven had $\mathrm{HbCO}$ and plasma bilirubin levels that were within, or close to, the range of the controls. The other two included a fetus with only slightly elevated $\mathrm{HbCO}$ levels measured on four occasions (range 0.0143 0.0170 ) and a severely hydropic fetus who died before receiving a transfusion (Fig. 5). In other fetuses who underwent transfusions sufficiently often to have their own erythrocytes completely replaced by donor cells, i.e. after the second in utero transfusion (27), $\mathrm{HbCO}$ and total plasma bilirubin levels reverted back toward normal. These observations support fetal hemolysis as the cause of the elevations in HbCO levels. Furthermore, the observation in individual fetuses studied serially suggests that maintaining fetal hematocrit levels $>0.30$ is sufficient for providing adequate oxygen-carrying capacity to suppress endogenous fetal erythropoiesis.

The four Coombs-negative anemic fetuses all had laboratory data consistent with fetal $\mathrm{HbCO}$ levels reflecting the degree of fetal hemolysis. In the three in which anemia was due to nonhemolytic causes, all had $\mathrm{HbCO}$ levels within the range of the controls. The remaining anemic Coombs-negative fetus had a systemic viral infection associated with a rapidly falling hematocrit, high reticulocyte count, and markedly elevated $\mathrm{HbCO}$ and plasma bilirubin levels.

Although only two of the 15 fetuses with hemolytic disease were hydropic, both had $\mathrm{HbCO}$ levels that were low relative to their concomitant $\mathrm{Hb}$ levels (Fig. 3). Moreover, in the one hydropic fetus in which bilirubin was measured, the value was low relative to the $\mathrm{Hb}$ concentration (Fig. 5). On the basis of these limited data, one might speculate that fetal hydrops is 
associated with dysfunctional heme degradation, i.e. a reduced capacity of the reticuloendothelial system for metabolizing hemolyzed blood.

In the group of 26 control fetuses, a significant inverse relationship of gestational age was observed for both the relative reticulocyte fraction and the absolute reticulocyte count. The relative fraction of reticulocytes, but not the absolute reticulocyte count, was significantly associated with $\mathrm{HbCO}$ when examined by multiple regression along with gestational age in the fetuses with hemolytic disease. This difference may be attributable to maternal antibodies in the fetal circulation causing an attenuation of what would otherwise have been a pronounced erythropoietic response to anemia. Under circumstances of immunemediated fetal anemia, a modest relative increase in reticulocytes might be anticipated without a concomitant increase in the absolute number.

Potential deleterious effect of $\mathrm{HbCO}$ on fetal oxygenation. Toxicity due to elevated $\mathrm{HbCO}$ levels is of concern in fetuses with hemolytic disease. $\mathrm{CO}$ exerts toxicity through its ability to displace oxygen from $\mathrm{Hb}$, through its effect on increasing $\mathrm{Hb}$ 's oxygen affinity, and through other less-well-understood mechanisms affecting nervous system function $(4,28)$. Documented toxic effects of $\mathrm{CO}$ in nonanemic fetal animals at $\mathrm{HbCO}$ levels above 0.08 include reduced birth weight $(29,30)$, increased neonatal mortality (29), congenital malformations (29), abnormal neuromuscular activity (31), and learning and memory deficits (30). Although the slightly increased levels of $\mathrm{HbCO}$ we observed in the majority of our slightly anemic fetuses with hemolytic disease are unlikely to cause significant impairment of tissue oxygenation, moderate $\mathrm{HbCO}$ levels in the range of $0.03-0.04$ in the few severely anemic fetuses might. HbCO levels of this magnitude could result in a $0.1-0.2 \mathrm{mmol} / \mathrm{L}$ reduction in the fetus's oxygen-carrying capacity. Although such a reduction may at first seem trivial, when placed in the context of a fetus whose tissue oxygen delivery is already impaired by the combined effects of severe anemia, a CO-induced left-shifted $\mathrm{Hb}$-oxygen dissociation curve, and heart and liver failure, the additional adverse impact of $\mathrm{HbCO}$ levels may not be inconsequential. The hypothetical adverse consequences of $\mathrm{HbCO}$ levels in anemic fetuses might best be studied directly in a chronically catheterized fetal animal model.

In summary, in fetuses with immune hemolytic disease from whom samples were taken before transfusion, modestly increased $\mathrm{HbCO}$ levels were found. In this group, severity of fetal anemia, as indicated by $\mathrm{Hb}$ concentration, was directly associated with the level of $\mathrm{HbCO}$. Statistical analysis of fetal laboratory parameters using multiple regression demonstrated that plasma bilirubin was the laboratory parameter most strongly correlated with $\mathrm{HbCO}$. The close direct association of these two variables suggests that $\mathrm{HbCO}$ and bilirubin are indicators of the degree of hemolysis in mid- to late-gestation human fetuses. This speculation is further supported by results observed in four anemic fetuses who did not have immune hemolytic disease and by results of individual anemic fetuses with immune hemolytic disease who underwent multiple cordocenteses. Because $\mathrm{HbCO}$ levels in fetuses with hemolytic disease were only modestly elevated relative to fetuses of mothers who smoked, the elevated $\mathrm{HbCO}$ levels in the former group are unlikely to have untoward physiologic effects. Although factors affecting $\mathrm{HbCO}$ levels in the blood of fetuses are complex, our findings support the hypothesis that $\mathrm{HbCO}$ levels are not only indicative of the severity of anemia before transfusion but also are indicative of the rapidity of fetal hemolysis. Proof for this latter speculation would require more frequent repeated fetal blood sampling than is currently ethically justifiable. A fetal animal model of laboratory-induced hemolysis would be useful in addressing these and other relevant issues.

Acknowledgments. The authors thank Robert L. Schmidt and Svetlana A. Alshvang for technical support, Leon F. Burmeister, Ph.D., for statistical advice, Louise C. Estle, R.N., for her inter- action with patients and sample handling, Sharon Mullin for editorial comments and Professor G. Bernaschek of the II Obstetrics Department at the University Hospital of Vienna for providing patient samples.

\section{REFERENCES}

1. Coburn RF, Williams WJ. White P, Kahn SB 1967 The production of carbon monoxide from hemoglobin in vivo. $\mathrm{J}$ Clin Invest 46:346-356

2. Sjostrand T 1949 Endogenous formation of carbon monoxide in man under normal and pathologic conditions. Scand J Clin Lab Invest 1:201-214

3. Berk PD, Blaschke TF, Scharschmidt BF. Waggoner JG, Berlin NI 1976 A new approach to quantitation of the various sources of bilirubin in man. $\mathrm{J}$ Lab Clin Med 87:767-780

4. EPA 1991 Air quality criteria for carbon monoxide. EPA 600/8-90/045F, Environmental Criteria and Assessment Office, Office of Health and Environmental Assessment, Office of Research and Development, U.S. Environmental Protection Agency, Research Triangle Park. NC

5. Tenhunen R, Marver HS. Schmid R 1968 The enzymatic conversion of heme to bilirubin by microsomal heme oxygenase. Proc Natl Acad Sci USA $61: 748-755$

6. Longo LD 1970 Carbon monoxide in the pregnant mother and fetus and its exchange across the placenta. Ann NY Acad Sci 174:313-341

7. Bowman JM 1988 Alloimmune hemolytic disease of the neonate. In: Stockman III JA. Pochedly C (eds) Developmental and Neonatal Hematology. Raven Press, New York, pp 223-248

8. Fällström SP, Bjure J 1967 Endogenous formation of carbon monoxide in newborn infants. II. Rh haemolytic disease of the newborn. Acta Paediatr Scand 56:365-373

9. Uetani Y, Nakamura J, Okamoto O, Yamazaki T, Vreman HJ, Stevenson DK 1989 Carboxyhemoglobin measurements in the diagnosis of ABO hemolytic disease. Acta Paediatr Jpn 31:171-176

10. Wranne L 1969 Studies on erythro-kinetics in infancy. XIV. The relation between anaemia and haemoglobin catabolism in $\mathrm{Rh}$-haemolytic disease of the newborn. Acta Paediatr Scand 58:49-53

11. Longo LD 1977 The biological effects of carbon monoxide on the pregnan woman, fetus, and newborn infant. Am J Obstet Gynecol 129:69-103

12. Leonard MB, Vreman HJ, Ferguson JE, Smith DW, Stevenson DK 1989 Interpreting the carboxyhemoglobin concentration in fetal cord blood. J Dev Physiol 11:73-76

13. Weiner CP, Williamson RA, Wenstrom KD. Sipes SL, Grant SS, Widness JA 1991 Management of fetal hemolytic disease by cordocentesis: I. Prediction of fetal anemia. Am J Obstet Gynecol 165:546-553

14. Weiner CP, Sipes SL, Wenstrom KD 1992 The effect of fetal age upon normal fetal laboratory values and venous pressure. Obstet Gynecol 79:713-718

15. Weiner CP 1987 Cordocentesis for diagnostic indications: two years' experience. Obstet Gynecol 70:664-668

16. Forestier F, Cox WL, Daffos F, Rainaut M 1988 The assessment of fetal blood samples. Am J Obstet Gynecol 158:1184-1188

17. Vreman HJ, Kwong LK, Stevenson DK 1984 Carbon monoxide in blood: an improved microliter blood-sample collection system. with rapid analysis by gas chromatography. Clin Chem 30:1382-1386

18. Vreman HJ, Stevenson DK, Zwart A 1987 Analysis for carboxyhemoglobin by gas chromatography and multicomponent spectrophotometry compared. Clin Chem 33:694-697

19. Ostrander CR, Cohen RS, Hopper AO, Cowan BE, Stevens GB, Stevenson DK 1982 Paired determinations of blood carboxyhemoglobin concentration and carbon monoxide excretion rate in term and preterm infants. $\mathrm{J} \mathrm{Lab} \mathrm{Clin}$ Med 100:745-755

20. Eilers RJ 1967 Notification of final adoption of an international method and standard solution for hemoglobinometry specifications for preparation of standard solutions. Am J Clin Pathol 47:212-214

21. Weiner CP 1992 Human fetal bilirubin and fetal hemolytic disease. Am J Obstet Gynecol 166:1449-1454

22. Coburn RF, Williams WJ, Kahn SB 1967 Endogenous carbon monoxide production in patients with hemolytic anemia. J Clin Invest 45:460-468

23. Engel RR, Rodkey FL, Krill CE 1971 Carboxyhemoglobin levels as an index of hemolysis. Pediatrics 47:723-729

24. Necheles TF, Rai UA, Valaes T 1976 The role of haemolysis in neonatal 
hyperbilirubinaemia as reflected in carboxyhaemoglobin levels. Acta Paediatr Scand 65:361-367

25. Engel RR, Rodkey FL, O'Neal JD, Collison HA 1966 Relative affinity of human fetal hemoglobin for carbon monoxide and oxygen. Blood 33:37-45

26. Maisels MJ, Pathak A, Nelson NM. Nathan DG. Smith CL 1971 Endogenous production of carbon monoxide in normal and erythroblastotic newborn infants. J Clin Invest 50:1-8

27. Weiner CP, Williamson RA, Wenstrom KD, Sipes SL, Widness JA, Grant SS, Estle L 1991 Management of fetal hemolytic disease by cordocentesis: II. Outcome of treatment. Am J Obstet Gynecol 165:1302-1307
28. Radford EP, Coburn RF, Bartlett D, Longo LD, Kuller LH, Ayres SM, Laties VG, Horvath SM 1977 Effects on man and animals. In: Carbon Monoxide. Committee on Medical and Biologic Effects of Environmental Pollutants, National Research Council, National Academy of Science, Washington, DC, pp 68-167

29. Astrup P, Trolle D. Olsen HM, Kjeldsen K 1972 Effect of moderate carbonmonoxide exposure on fetal development. Lancet $2: 1220-1222$

30. Mactutus CF, Fechter LD 1984 Prenatal exposure to carbon monoxide learning and memory deficits. Science 223:409-411

31. Koos BJ, Matsuda K, Power GG 1988 Fetal breathing and sleep state responses to graded carboxyhemoglobinemia in sheep. J Appl Physiol 65:2118-2123 